\title{
The Kids Are Alright: Taking Stock of Generational Differences at Work
}

\author{
Cort W. Rudolph \\ Saint Louis University
}

\author{
Hannes Zacher \\ Leipzig University
}

Discussions of the influence of generational differences -- the notion that there are demonstrable dissimilarities between members of different groupings of successive birth cohorts that manifest as differences in work outcomes -are ubiquitous in both the popular business and management literature and across various topics of research in the $\mathrm{IO} / \mathrm{OB} / \mathrm{HR}$ realm. For example, recent surveys of the "Top 10 Workforce Trends" published by SIOP since 2015 all recognize that, in some capacity, generations and the differences (that are assumed to exist) between them have some bearing on the type of work that we do as IO psychologists (e.g., SIOP, 2016). The SIOP website has likewise featured news releases and blog postings on the topic of generational differences (e.g., SIOP, 2010; 2012). Additionally, since 2013, the APA's "Work and Well-Being Survey" reports the results of a number of generational group comparisons for several work outcomes (e.g., work stress, job satisfaction, involvement), ostensibly as a means of demonstrating the effect that generational membership has on such outcomes (e.g., APA, 2017). Finally, in 2015, a focal article on generational differences featured in Industrial and Organizational Psychology: Perspectives on Science and Practice invited commentary on ideas surrounding generational differences at work (Costanza \& Finkelstein, 2015).

Although these observations do speak to the emergence and popularity of thinking about generational differences in our field, we face an important question when considering the broader implications of this phenomenon: "What influence does the notion of generational differences actually have on those processes that we care about as IO researchers and practitioners?" Here, we take a balanced look at this question, with the hope of providing some practical guidance to IO researchers and practitioners about how to address the topic of generational differences in their own work.

While increasingly popular, the notion of generational differences is not without its critics. Our own work on this topic has generally called into question a number of the assumptions made by both theories of generations and research that has purported to study differences between generations (Rudolph, 2015; Rudolph \& Zacher, 2015; Rudolph \& Zacher, 2017a, 2017b; Rudolph, Rauvola, \& Zacher, 2017; Zacher, 2015a). Through our research, writing, and discussions with colleagues -- both academics and practitioners -- it is clear to us that this topic can be quite divisive. People tend to take a hard line on their opinions regarding the existence (or nonexistence) of generations and the assumed differences between them. We would argue that it is precisely this divisiveness that makes this topic of particular importance to explore and critique. To further this conversation, we next consider two competing positions suggesting, on the one hand, that generational differences matter, and on the other hand, that they do not.

\section{Arguments in Favor of Generational Differences}

Generations as a construct for empirical study emerged from functionalist sociological theories in the early-to-mid $20^{\text {th }}$ century (e.g., Mannheim, 1927/1952; Ryder, 1965). These early 
sociological theorists sought an explanation for aggregate-level changes that are experienced by societies over time (e.g., political movements), and the notion of generation-to-generation shifts in attitudes and values was introduced to explain such changes. From a functionalist sociological lens, each new generation (i.e., in the sense of the lineage of successive birth cohorts from year-toyear) brings facets of their unique experiences to bear on the problems faced by their society. Accordingly, when considered in the aggregate (i.e., across members of a given birth cohort), the collective experiences of each generation serve to shape how social changes unfold within a given society, at a particular point in time (see Kertzer, 1983 , for a review of these early perspectives).

Related perspectives on generations are, to some extent, reflected in early writings in developmental psychology, which address the possibility that societal influences shape the nature of human development. For example, in 1904, G. Stanley Hall suggested: "Never has youth been exposed to such dangers of both perversion and arrest as in our own land and day" (Vol. I, p. 15). The adoption of the generations perspective by the $\mathrm{IO} / \mathrm{OB} / \mathrm{HR}$ literature can likewise be traced across time. Indeed, generational differences have long been invoked to explain changes in work-relevant attitudes, behaviors, and motives (e.g., Smola \& Sutton, 2002). For example, there are early references to the role of generational differences and the influence of "generation gaps" in leadership and management phenomena (e.g., DeSalvia \& Gemmil, 1971; Diamant, 1960; Paul \& Schooler, 1970). More than twenty years ago, Tulgan (1995) offered guidance regarding "Managing Generation X." More recently, Schein (2004) discusses the role of generations in transmitting culture within organizations. A recent edited volume of academic works has likewise been dedicated to exploring these and related issues (Burke, Cooper, \& Antoniou, 2015).

Arguments in favor of generational differences often cite the observation that the workforce and/or the workplace are changing at a rapid pace, and it would be difficult to refute either of these points. The workforce, and hence organizations, are becoming increasingly age diverse (Rudolph, Marcus, \& Zacher, In Press). The way in which work is being done is changing and the nature of the work itself is changing concurrently (e.g., Frese, 2000). In research, theories of generational differences are often invoked to explain such changes, either as an antecedent to change (e.g., generational differences explain differentiated career patterns; Lyons, Schweitzer, \& Ng, 2015) or as a reflection of change itself (e.g., members of different generations react differently to economic recessions; De Hauw \& De Vos, 2010). Regardless of the how generations are invoked (i.e., as an antecedent or consequence of change), generational differences research is typically grounded in the aforementioned sociological notion that growing up in a certain time-and-place systematically and predictably shapes the attitudes, values, and ultimately the behaviors of the members of different generational cohorts.

Extending this research to $\mathrm{IO} / \mathrm{OB} / \mathrm{HR}$ practice, advice is often given on how to best manage generational differences in the workplace. A casual stroll through any airport bookstore reveals a variety of popular-press books that exist and speak to these and related ideas (e.g., Espinoza \& Ukleja, 2016). Also speaking to applications, a Google search for the phrase "managing generational differences" offers nearly 20,000 results, ranging from summaries of best practices for managing workers of different generational groups, to elaborately-developed off-the-shelf training programs that likewise focus on preparing managers to apply such practices to their own multigenerational workforces.

Given the ubiquity of, and weight placed upon the notion of generational differences in the popular business and management literature, it is somewhat surprising how little empirical research is actually conducted on generational differences at work (e.g., a comprehensive meta-analysis of this literature from 2012 by Costanza, Badger, Fraser, Severt, \& Gade only considered $K=20$ studies). Although this lack of research is likely due in part to the various methodological hurdles associated with this area of inquiry (reviewed in 
some detail later in this piece), a recent special issue of Work, Aging and Retirement includes several important conceptual and empirical advances that inform this area of study (See Costanza \& Finkelstein, 2017). Beyond generational differences, organizational researchers have focused on related generationlike phenomena, for example generational identity at work (e.g., Joshi, Dencker, Franz, \& Martocchio, 2010) and the value of intergenerational exchanges in the workplace (e.g., Henry, Zacher, \& Desmette, 2015).

Recently, proponents of generational differences have offered that generational categories are a useful means of understanding how socio-cultural phenomena manifest as age-related differences that can influence individual level behaviors. For example, according to Twenge $(2017$, p. 6):

"Any generational cutoff is arbitrary; there is no exact science or official consensus to determine which birth years belong to which generation. [...] Nevertheless, generational labels with specific cutoffs are useful...they allow us to define and describe people despite the obvious limitations of using a bright line when a fuzzy one is closer to the truth."

The contemporary understanding of generations offered by Twenge (2017) reflects the socialconstructivist perspective on generational differences that we have proposed and discussed elsewhere (e.g., Rudolph \& Zacher, 2015; 2017a). Specifically, this perspective acknowledges that generations (and hence, differences between them) do not really exist in an objective sense, rather they are socially constructed to explain the complexities of changing societies against the intricacies of human development that we observe on a day-to-day basis, and particularly when interacting with people of different ages and life stages. From a social-constructivist perspective, thinking in terms of generations is useful for making a complex issue (i.e., aging) less complex, and giving meaning to observations and perceptions of age-related differences that we witness via social interactions.

\section{Arguments Opposed to Generational Differences}

Critics of generational differences applied to the study of work often suggest that the focus on such differences in both research and practice is more indicative of a "management fad" (i.e., a fashionable and novel-yet-unsubstantiated idea, see Abrahamson, 1991; 1996; Røvik, 2011) than an empirically discernable phenomenon. Such critiques are based on a number of logical, empirical, and methodological concerns that have been noted in research that purports to study generations and generational differences.

From a logical perspective, applying generational theorizing to elucidate work-related phenomena represents a top-down, deterministic (i.e., in that it assumes that all members of a given generation "act" in the same way) and reductionist (i.e., a great deal of nuance is lost when distilling otherwise complex aging phenomena into simpler "generational" units) way of explaining behavior. Furthermore, the application of generational explanations involves exploring relationships among variables defined and measured at different conceptual levels of analysis (i.e., generations are typically defined at the group level, and work outcomes at the individual level). As such, generations research begets the possibility of committing either atomistic (i.e., inferences regarding variability across groups based on individual level data) or ecological (i.e., inferences regarding phenomena at the individual level on the basis of group level data) fallacies. As discussed further below, the latter fallacy is of particular concern to various cross-temporal methods that are often used to study generational differences phenomena (e.g., Twenge et al., 2010; Wegman et al., in press).

From an empirical perspective, there is meager evidence to support the existence of generational differences phenomena. The aforementioned meta-analysis by Costanza et al. (2012) failed to find support for generational differences across a number of work outcomes, and a recent qualitative review by Stassen, Anseel, and Levecque (2016) triangulates this conclusion. Another recent meta- 
analysis found no generational differences in work ethic endorsement (Zabel et al., 2017). A review on generational differences in the workplace by Lyons and Kuron (2014) concluded that "... evidence has been sparse for some variables and inconsistent for others. There remains a great deal of variation in methodologies and reporting of findings, making it difficult to draw definitive conclusions from the research" (p. S153). Additionally, our recent review of the leadership and generations literature (Rudolph, Rauvola, \& Zacher 2017) likewise failed to find compelling support that generational differences are present in leadership-related phenomena.

Beyond the results of these quantitative and qualitative reviews of this literature, it is also important to recognize that the means of assessing generational effects via statistical methods has important implications to this area of study. To this end, in a study applying various common statistical models for analyzing data for the presence of generational differences, Costanza, Badger-Darrow, Yost, and Severt (2017) find that these methods do not converge with one another. This suggests that any conclusions one could draw regarding generational differences are, in part, dependent upon the statistical approach to analysis. We think this to be a troubling observation, indeed. Recently, among otherwise staunch proponents of generational differences, doubt has been cast upon generations as they have been understood in organizational research (i.e., Campbell, Twenge, \& Campbell, 2017, described generations as "fuzzy social constructs").

Finally, methodologically, generational differences research typically uses single time point (i.e., cross-sectional) research designs. Cross-sectional methods cannot be used to address questions about generations, because of the conflation of chronological age, contemporaneous period, and birth cohort effects -- each of which is confounded with one-another in such designs. As a simple example of this confounding phenomenon, consider that if the current year is known (e.g., 2017) along with one's age (e.g., 35), then their birth cohort is determined (i.e., 1982). In a single time point study, the year of data collection is (most typically) held constant. Thus, conclusions drawn with respect to birth cohort effects (i.e., which are usually offered as evidence of generational differences) could be due to either birth cohort or chronological age; each is equally likely to be the (assumed causal) mechanism at play. From this, it is up to theory to parse these confounded sources of variance. Thus, crosssectional methods cannot draw valid conclusions about generational differences.

So-called cross-temporal methods (e.g., Twenge et al., 2010) have also been advanced to circumvent to some degree the problems of ageperiod-cohort confounding. However, these methods are likewise burdened with the same concerns over confounding of cohort and period effects and a reliance on inferences based upon ecological relationships. More specifically, crosstemporal methods hold age constant across time (e.g., looking at independent samples of 35 year olds, sampled in 1990, 2000, and 2010). In holding age constant, cohort and period effects are confounded with one another, such that each are equally likely causes of observed variation, and it is again up to theory to parse their unique effects. Thus, just like cross-sectional methods, crosstemporal methods cannot draw valid conclusions about generational differences. Furthermore, because cross-temporal methods draw inferences on the basis of correlations between group-level phenomena, they present a special case of the ecological correlation -- a long acknowledged statistical misspecification (see Robinson, 1950).

To our knowledge, nearly every study of generational difference effects in work outcomes has adopted either a cross-sectional or crosstemporal methodology (c.f., Kowske, et al., 2010). Given the limitations of each of these methodologies for studying generational differences that we have noted here (and, if we abstract these ideas to an admittedly extreme position) it could be argued that there has never actually been an empirical study of generational differences in work outcomes! Importantly, even if research were to adopt developmental psychology's "gold standard" cohort-sequential research design (i.e., a type of longitudinal design 
in which different birth cohorts are sampled over several years or even decades, see Baltes, 1968) and use advanced cross-classified mixed effects modeling procedures (e.g., Kowske, et al., 2010), a number of the logical and statistical problems associated with studying generations (e.g., arbitrary age boundaries, ecological fallacies, noncausal parameters, endogeneity) would still remain.

\section{Conclusions}

We originally posed the question, "What influence does the notion of generational differences actually have on those processes that we care about as IO researchers and practitioners?" To further contextualize our previous discussion and answer this question, we now consider the conclusions that we can draw from the available evidence. Holding back the logical and methodological arguments against generational differences, and at the risk of being polemic and/or dismissive, we would suggest that there currently is not sufficient empirical evidence for generational differences to warrant all of the attention that this idea receives in research and practice. Moreover, when considering the paucity of evidence supporting the existence of generational differences in work outcomes and the logical and methodological arguments that limit our ability to define their existence, this position is even further cemented. In terms of practical guidance, we would strongly caution against applying generational differences to explain noted shifts in work-related processes, broadly defined.

In our work, we have thus called for a moratorium to be placed on research on generations and generational differences, and suggested adopting a more differentiated lifespan developmental perspective on age-related phenomena (e.g., Rudolph \& Zacher, 2017a,b). The lifespan perspective that we have advocated for conceptualizes individual development as a continuous, multidimensional, and multidirectional process that is influenced by normative and idiosyncratic individual and contextual factors (Baltes, 1987). To further advance our position, Table 1 offers four pieces of practical (and actionable) advice for how to begin adopting such a lifespan perspective. In closing, we recognize that generational differences do provide a convenient wrapper for more complex age-based explanations. However, we would argue that with respect to generational differences, this convenience accompanies a litany of expenses that cancel out their expediency.

Table 1.

Four Ways to Adopt a Lifespan Perspective on Aging at Work

1. Recognize age-related changes in abilities (e.g., physical and cognitive capacities) and the impact that such changes bring to bear on job performance and related outcomes (e.g., work motivation).

2. Understand age-related difference in life situations (e.g., temporal shifts in work versus non-work roles and their associated demands) and offer age-conscious policies and provisions to support the work-life interface (e.g., familycare, including childcare and eldercare; flexible time and place policies)

3. Acknowledge temporal dynamics in individual differences (e.g., the age-graded re-organization of personality and motives; the accrual of tacit and explicit job knowledge and related job skills) and how these dynamics influence various work processes and outcomes.

4. Advocate for the design of work systems that optimally integrate various age-related changes, differences, and dynamics (e.g., institute complete-task job design to promote long term wellbeing and performance; afford workers the latitude to proactively self-manage work tasks and responsibilities via job crafting) 


\section{References}

APA (2017, May 24). 2017 Work and Well-Being Survey. Retrieved October 17, 2017 from: http://www.apaexcellence.org/assets/general/2017work-and-wellbeing-surveyresults.pdf? ga $=2.234282266 .563601534 .150690018$ 4-1206449101.1490975377

Abrahamson, E. (1991). Managerial fads and fashions: The diffusion and rejection of innovations. Academy of Management Review, 16, 586-612. doi:10.2307/258919

Abrahamson, E. (1996). Management fashion. Academy of Management Review, 21, 254-285. doi:10.5465/AMR.1996.9602161572

Baltes, P. B. (1987). Theoretical propositions of lifespan developmental psychology: On the dynamics between growth and decline. Developmental Psychology, 23(5), 611.626.

Bennett, M. M., Beehr, T. A., \& Ivanitskaya, L. V. (2017). Work-family conflict: differences across generations and life cycles. Journal of Managerial Psychology, 32(4) 314-332. doi: 10.1108/JMP-06-2016-0192

Burke R.J., Cooper C.L., Antoniou A.S. (2015) The multi-generational and aging workforce: Challenges and opportunities. Edward Elgar, Cheltenham, England.

Campbell, S. M., Twenge, J. M., \& Campbell, W. K. (2017). Fuzzy but useful constructs: Making sense of the differences between generations. Work, Aging and Retirement, 3, 130-139.

10.1093/workar/wax001

Costanza, D. P., \& Finkelstein, L. M. (2015). Generationally based differences in the workplace: Is there a there there? Industrial and Organizational Psychology, 8(3), 308-323. doi: 10.1017/iop.2015.15

Costanza, D. P., \& Finkelstein, L. M. (2017). Generations, Age, and the Space Between: Introduction to the Special Issue. Work, Aging and Retirement, 3(2), 109-112. doi:

10.1093/workar/wax003

Costanza, D. P., Badger, J. M., Fraser, R. L., Severt, J. B., \& Gade, P. A. (2012). Generational differences in work-related attitudes: A meta-analysis. Journal of Business and Psychology, 27, 375-394. doi:10.1007/s10869-012-9259-4
Costanza, D. P., Darrow, J. B., Yost, A. B., \& Severt, J. B. (2017). A review of analytical methods used to study generational differences: Strengths and limitations. Work, Aging and Retirement, 3, 149165. doi:10.1093/workar/wax002

DeSalvia, D. N., \& Gemmill, G. R. (1971). An exploratory study of the personal value systems of college students and managers. Academy of Management Journal, 14, 227-238. doi: $10.2307 / 255309$

Diamant, A. (1960). The relevance of comparative politics to the study of comparative administration. Administrative Science Quarterly, 5, 87-112. doi: $10.2307 / 2390826$

Espinoza, C., \& Ukleja, M. (2016). Managing the millennials: Discover the core competencies for managing today's workforce ( $2^{\text {nd }}$ Edition). New York, NY: John Wiley \& Sons.

Frese, M. (2000). The changing nature of work. In N. Chmiel (Ed.), Introduction to work and organizational psychology (pp. 424-439). Oxford, UK: Blackwell.

Hall, G. S. (1904). Adolescence: Its psychology and its relations to physiology, anthropology, sociology, sex, crime, religion, and education (Vols. I \& II). New York, NY: D. Appleton \& Co.

Henry, H., Zacher, H., \& Desmette, D. (2015). Reducing age bias and turnover intentions by enhancing intergenerational contact quality in the workplace: The role of opportunities for generativity and development. Work, Aging and Retirement, 1(3), 243-253. doi: 10.1093/workar/wav005

Joshi, A., Dencker, J. C., Franz, G., \& Martocchio, J. J. (2010). Unpacking generational identities in organizations. Academy of Management Review, 35(3), 392-414. doi: 0.5465/AMR.2010.51141800

Kertzer, D. I. (1983). Generation as a sociological problem. Annual Review of Sociology, 9, 125-149. doi:10.1146/annurev.so.09.080183.001013

Kowske, B. J., Rasch, R., \& Wiley, J. (2010). Millennials' (lack of) attitude problem: An empirical examination of generation effects on work attitudes. Journal of Business and Psychology. 25(2), 265-279. doi: 10.1007/s10869-010-9171-8 
Mannheim, K. (1952). The problem of generations. In P. Kecskemeti (Ed.), Essays in the sociology of knowledge (pp. 276-322). Boston, MA: Routledge \& Kegan Paul. (Original work published 1927)

Paul, R. J., \& Schooler, R. D. (1970). An analysis of performance standards and generation conflict in academia. Academy of Management Journal, 13, 212-216. doi: 10.2307/255109

Robinson, W. S. (1950). Ecological correlations and the behavior of individuals. American Sociological Review, 15, 351-357. doi: $10.2307 / 2087176$

Røvik, K. A. (2011). From fashion to virus: An alternative theory of organizations' handling of management ideas. Organization Studies, 32, 631653. doi: 10.1177/0170840611405426

Rudolph, C. W. (2015). A note on the folly of crosssectional operationalizations of generations. Industrial and Organizational Psychology, 8, 362366. doi: 10.1017/iop.2015.50

Rudolph, C. W., Marcus, J., \& Zacher, H. (in press). Global issues in work and aging. In K. Shultz \& G. Adams (Eds.), Aging \& work in the 21st century, 2nd edition. Routledge/Psychology Press.

Rudolph, C. W. \& Zacher, H. (2015). Intergenerational perceptions and conflicts in multi-age and multigenerational work environments. In L. Finkelstein, D. Truxillo, F. Fraccaroli, F., \& R. Kanfer (Eds.), SIOP Organizational Frontier Series Facing the challenges of a multi-age workforce: $A$ use-inspired approach (pp. 253-282). New York, NY: Psychology Press.

Rudolph, C. W., \& Zacher, H. (2017a). Considering generations from a lifespan developmental perspective. Work, Aging and Retirement, 3, 113129. doi: 10.1093/workar/waw019

Rudolph, C. W., \& Zacher, H. (2017b). Myths and misconceptions about leading generations: Setting the record straight. In T. A. Scandura \& E. Mouriño (Eds.), Leading diversity in the 21st century (pp. 243-278). Charlotte, NC: Information Age Publishing.

Rudolph, C.W., Rauvola, R.S., \& Zacher, H. (2017). Leadership and generations at work: a critical review. Leadership Quarterly. [In Press Accepted Manuscript].
Ryder, N. B. (1965). e cohort as a concept in the study of social change. American Sociological Review, 30, 843-861. doi:10.2307/2090964

Schein, E. H. (2004). Organizational culture and leadership ( $3^{\text {rd }}$ ed.). San Francisco, CA: Jossey-Bass.

Smola, K., \& Sutton, C. D. (2002). Generational differences: Revisiting generational work values for the new millennium. Journal of Organizational Behavior, 23, 363-382.

Stassen, L., Anseel, F., \& Levecque, K. (2016). Generatieverschillen op de werkvloer: What people believe is true is frequently wrong. Gedrag \& Organisatie, 29, 86-92.

Lyons, S., \& Kuron, L. (2014). Generational differences in the workplace: A review of the evidence and directions for future research. Journal of Organizational Behavior, 35, S139-S157. doi:10.1002/job.1913

Lyons, S. T., Schweitzer, L., \& Ng, E. S. (2015). How have careers changed? An investigation of changing career patterns across four generations. Journal of Managerial Psychology, 30(1), 8-21. doi: 10.1108/JMP-07-20140210

SIOP (2010, June 9). Millennials on a Mission: SIOP Members' Research Finds Gen Y Employees More Motivated to Learn and Use Training Than Gen Xers. Retrieved October 2, 2017 from: http://www.siop.org/Media/News/gen_y.aspx

SIOP (2012, July 18). Studying Generation C in the Workplace. Retrieved October 2, 2017 from: http://www.siop.org/article_view.aspx?article=994

SIOP (2016, December 20). SIOP Announces Top 10 Workplace Trends for 2017. Retrieved October 17, 2017 from: http://www.siop.org/article_view.aspx?article $=1610$

Tulgan, B. (1995), Managing generation X: How to bring out the best in young talent. Santa Monica, CA: Merritt Publishing Company.

Twenge, J. M. (2017). IGen: Why Today’s SuperConnected Kids Are Growing Up Less Rebellious, More Tolerant, Less Happy--and Completely Unprepared for Adulthood--and What That Means for the Rest of Us. New York: Simon and Schuster. 
Twenge, J. M., Campbell, S. M., Hoffman, B. J., \& work values: Leisure and extrinsic values increasing, social and intrinsic values decreasing. Journal of Management, 36(5), 1117-1142. doi:

$10.1177 / 0149206309352246$

Wegman, L. A., Hoffman, B. J., Carter, N. T., Twenge, J. M., \& Guenole, N. (In Press). Placing job characteristics in context: cross-temporal metaanalysis of changes in job characteristics since 1975. Journal of Management. doi: $10.1177 / 0149206316654545$

Zacher, H. (2015). Using lifespan developmental theory and methods as a viable alternative to the study of generational differences at work. Industrial and Organizational Psychology, 8, 342346. doi: 10.1017/iop.2015.47

Zabel, K. L., Biermeier-Hanson, B. B., Baltes, B. B., Early, B. J., \& Shepard, A. (2017). Generational differences in work ethic: Fact or fiction?. Journal of Business and Psychology, 32(3), 301-315. doi: 10.1007/s10869-016-9466-5 